$\begin{array}{ll} & \text { Etnográfica } \\ \text { etnográfica } & \text { Revista do Centro em Rede de Investigação em }\end{array}$

Antropologia

vol. 20 (3) | 2016

Vol. $20(3)$

\title{
O uso do crack como ele é: o cachimbo, o "bloco" e o
} usuário

The use of crack as it is: the pipe, the "block" and the user

\section{Ygor Diego Delgado Alves}

\section{(2) OpenEdition}

\section{Journals}

\section{Edição electrónica}

URL: https://journals.openedition.org/etnografica/4640

DOI: $10.4000 /$ etnografica. 4640

ISSN: 2182-2891

\section{Editora}

Centro em Rede de Investigação em Antropologia

\section{Edição impressa}

Data de publição: 1 outubro 2016

Paginação: 495-515

ISSN: 0873-6561

\section{Refêrencia eletrónica}

Ygor Diego Delgado Alves, «O uso do crack como ele é: o cachimbo, o "bloco" e o usuário», Etnográfica [Online], vol. 20 (3) | 2016, posto online no dia 27 novembro 2016, consultado o 09 fevereiro 2022. URL: http://journals.openedition.org/etnografica/4640 ; DOI: https://doi.org/10.4000/etnografica.4640

\section{(c) (7) \&}

Etnográfica is licensed under a Creative Commons Attribution-NonCommercial 4.0 International License. 


\section{O uso do crack como ele é: o cachimbo, o "bloco" e o usuário}

\section{Ygor Diego Delgado Alves}

Com o objetivo de obter um bom "trago", ou seja, consumir satisfatoriamente o crack, seus usuários desenvolveram uma rica parafernália, assim como valores relacionados com a boa convivência e rituais de uso. O propósito coletivo de obter prazer consumindo, a cada tragada, uma fração da "pedra" de crack contribui para que certas relações se estabeleçam, nos locais de uso, em torno de papéis sociais específicos, como os de "vapor", "contenção" e "parasita”. A partir de pesquisa etnográfica, realizada na região central da cidade de São Paulo, pôde-se acompanhar diferentes grupos de usuários com suas práticas e representações.

PALAVRAS-CHAVE: consumo do crack, etnografia, ritual de uso, parafernália.

The use of crack as it is: the pipe, the "block" and the user - In order to get a good pull, meaning to satisfactorily consume crack, its users developed a rich paraphernalia, as well as values related to convivial relationships and rituals of use. The common purpose of obtaining pleasure by consuming, gradually, a fraction of the crack "rock" contributes to the establishment of certain relationships, in places of consumption, around specific social roles. Through ethnographic research, conducted in the central area of São Paulo, it was possible to follow different user groups, their practices and representations.

KEYWORDS: crack consumption, ethnography, ritual of use, paraphernalia.

ALVES, Ygor Diego Delgado (antropologiaygor@yahoo.com.br) - Programa de Saúde Coletiva, Unifesp, Brasil. 


\section{INTRODUÇÃO}

A pesquisa que deu origem a este artigo foi realizada sob a orientação do antropólogo Edward MacRae e fez parte do doutoramento em Antropologia Social realizado pelo autor na Universidade Federal da Bahia. Deu-se entre os anos de 2013 e 2014, na região central da cidade de São Paulo, mais especificamente na região conhecida como Cracolândia, e em dois outros locais de uso e comércio de crack localizados no bairro do Cambuci, também na região central da cidade. Contou, em seu início, com o auxílio de um informante privilegiado pertencente ao círculo mais próximo do autor, cultural e socialmente. Foi uma imersão de caráter etnográfico no campo, com o pesquisador convivendo com diferentes usuários e grupos de usuários de crack por tempo não inferior a um ano e meio.

Pretende-se analisar como o uso do crack proporcionou a criação de uma rica parafernália, composta por ferramentas e utensílios dos mais variados, para a obtenção do melhor "trago" possível. Esse uso também impulsionou o desenvolvimento de uma verdadeira tecnologia do disfarce, o "barraco", feito com materiais disponíveis no ambiente urbano, utilizados para as necessidades próprias do contexto delicado do proibicionismo. Estes artefatos relacionam-se com os padrões de consumo da droga e rituais dos usuários, ao serem trocados, compartilhados, vendidos, desmontados e refeitos ao sabor das necessidades e possibilidades dos consumidores de crack. Os artefatos ainda se prestam a prevenir danos, compor e demonstrar adesão a certos tipos identitários e corporalidades. Assim, as estratégias de redução de danos acabam confrontando-se com estas práticas nas cenas de uso.

Partiremos do cachimbo para chegar ao "fumódromo" e nesta "caminhada" 1 teremos a oportunidade de ter uma breve mirada sobre alguns dos objetos produzidos pelo gênio craqueiro. Seu uso foi acompanhado na prática, nas ocasiões em que são trocados, compartilhados, vendidos, desmontados e refeitos em sua mediação com o corpo.

\section{O “MAQUINÁRIO” E O CACHIMBO}

"Maquinário" é a categoria nativa para designar a parafernália utilizada no consumo do "bloco", ou "pedra" de crack. O cachimbo é o principal artefato deste conjunto e a maior realização artesanal do gênio craqueiro. ${ }^{2} \mathrm{Na}$ webpage da Confraria dos Amigos do Cachimbo, a descrição do ato de fumar assim

l "Passar a caminhada": dar um conjunto de instruções; "minha caminhada": a história de vida do usuário; "sair numa caminhada": percorrer certa distância, geralmente a pé.

2 Por si só o cachimbo pode ser considerado um importante agente na fruição da "pedra" de crack: "[...] eu sinto diferença porque se eu fumar a "pedra" no cachimbo o tuim dela é mais forte do que na lata $[\ldots]$ na minha concepção a adrenalina no coração fica mais forte [...] aquela sensação de medo e da paranoia fica muito mais louca do que fumar ela [pedra] na lata. O cachimbo em si, por causa do caninho, a sensação é mais louca mesmo [...]" (Oliveira 2007: 101). 


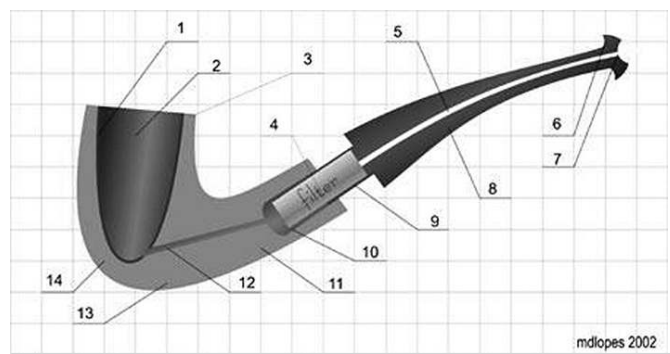

1. "Bolo"

2. Câmara do fornilho

3. Topo

4. Filtro

5. Canal de ar da haste

6. Lábios da boquilha

7. Boquilha

8. Haste

9. Encaixe da haste
10. Câmara de condensados

11. Pescoço do fornilho - haste

12. Canal de ar do fornilho

13. Base

14. Fornilho

Figura 1 - Cachimbo de tabaco e suas partes constitutivas

(Fonte: http://www.amigosdocachimbo.com.br/artigos/art_cachimbo_fumar.htm).

aparece: "Fumar cachimbo é adaptar um ritual ocioso de descontração e prazer, que requer atenção, destreza e conhecimento. Talvez seja esta a razão que leva a generalidade das pessoas associe o cachimbo a pessoas nobres e profissionais" (Castro s. d.). Veremos como o cachimbo de fumar crack, ou "Boris", também faz jus a estas observações, principalmente com respeito à atenção, destreza e conhecimento. Então, vejamos.

O crack pode ser fumado de diversas maneiras, em latas dobradas e perfuradas, em copos de água mineral descartáveis sobre furo na tampa de alumínio, em copos de Yakult ${ }^{3}$ com o mesmo furo na tampa e um "caninho", ${ }^{4}$ em cotovelos de tubulação de PVC, em lâmpadas e narguilés. Porém, em São Paulo, o cachimbo é o instrumento mais utilizado e fumar em cachimbo não é uma invenção dos craqueiros, mas costume muito difundido desde o consumo do "pito de pango", ou maconha, em "maricas" 5 (Alves 1998: 125). Assim, utilizaremos o cachimbo curvo de fumar tabaco para comparar, em seus elementos constitutivos e práticas de manuseio, com o cachimbo mais comum encontrado por nós dedicado ao uso do crack. Esta comparação irá mostrar continuidades entre as práticas e mesmo entre as representações sobre este costume. O cachimbo ou "Boris" é, na maioria das vezes, arranjado todo em metal. A haste e seu encaixe costumam ser uma mesma peça, o "caninho". O encaixe se adapta comumente de modo direto ao fornilho, sem a necessidade de um pescoço que sirva de ligação entre os dois. Isto proporciona a passagem direta da fumaça que se pretende sorver, do fornilho à haste. O "Boris" não costuma ser curvo, mas direito, termo usado pelos usuários de tabaco para referirem-se aos cachimbos retos, aqueles nos quais o conjunto da haste forma um ângulo reto com o fornilho. Isto facilita a retirada dos restos de tabaco e saliva que possam impregnar seu interior. $\mathrm{O}$ cachimbo de fumar tabaco existe previamente ao de

3 Yakult é uma marca de iogurte líquido vendida no Brasil.

4 "Caninho": tubo metálico, como os de antena de automóvel, utilizado nos cachimbos de crack.

5 "Maricas": antigos cachimbos utilizados para se consumir fumo e maconha, feitos geralmente de madeira. 
consumir crack; porém, é possível que sempre estivesse presente como ideia. $\mathrm{Na}$ relação entre estes objetos e os usuários, o copo de água mineral ${ }^{6}$ foi deixado de lado e o "caninho" acrescentado. No entanto, será na "rapa" que poderemos encontrar o agenciamento capaz de promover este processo de mudança.

Para os consumidores de tabaco, a borra ou resíduo aderente às paredes da câmara e canal do fornilho, assim como ao canal da haste, é algo a ser retirado para evitar-se o entupimento do sistema e que depois é descartado. Para os usuários de crack, a "rapa" é valiosa, unanimemente tida como de poder superior ao "bloco" ("pedra" de crack). Os lábios da boquilha são do mesmo material da haste, muitas vezes metálico, o que leva a seu grande aquecimento após o contato reiterado da chama com a base do fornilho, o que ocorre caso se deseje "atochar" (ou "tochar") o cachimbo. Dá-se esse nome ao modo de consumir a "rapa" sem retirá-la, mas pelo aquecimento do "fogãozinho" (ou fornilho) e do "caninho".

A queima da "pedra" é feita não no interior do fornilho, como no consumo de tabaco, mas em uma inovação feita sobre a tampa da câmara do fornilho tradicional, o "alumínio". Ele é geralmente proveniente de tampa de copo de água descartável e posteriormente perfurado. Segundo os depoimentos colhidos em nossa etnografia, o início do consumo do crack na cidade de São Paulo deu-se sobre o alumínio perfurado de copos de água descartáveis; assim, podemos afirmar de modo sintético que o copo tornou-se "fogãozinho", o alumínio perfurado foi mantido e acrescentou-se uma haste, ou "caninho". ${ }^{7}$ Neste caso, do uso em copos descartáveis, o usuário ou os usuários que fumassem uma quantidade razoável de "pedras", dez, por exemplo, poderiam retirar a "rapa" da tampa de alumínio do copo, e se usassem água em seu fundo, a "rapa" boiaria sobre ela e seria retirada em um processo difícil e pouco eficiente. A "rapa" e o desejo de obtê-la desestabilizou o conjunto copo/cinza/alumínio na prática do uso e até hoje; juntamente com o "trago" e os outros materiais, continua a provocar transformações.

Após fumar uma quantidade de crack, a cinza utilizada já não serve mais para nova dose e deve ser substituída por cinza nova. O cigarro, desta forma, é presença indispensável nas "rodas de pedra" e novos suprimentos são muito bem recebidos. Mas podem ser muito pouco fumados e não poucos usuários de crack são abstêmios de tabaco. Um cigarro pode ser aceso e, depois de comedida fumada, muitas vezes sem tragar, deixado queimar em posição vertical até que

6 Os primeiros usuários de crack se valiam de um copo de água mineral para consumir a "pedra". Ela era colocada sobre um buraco feito sobre a tampa de alumínio, coberto por cinzas de cigarro. Na cidade do Rio de Janeiro, o copo de água descartável ainda é largamente utilizado.

7 O mesmo é válido para a embalagem de Yakult: nela se fumava o crack sobre o alumínio original perfurado com o acréscimo de cinzas para evitar o escoamento do crack derretido em sua combustão para dentro da embalagem. O "caninho" já era usado neste sistema mais próximo do cachimbo atual que a lata e o copo. 
todo o fumo seja transformado na desejada cinza. Após sua queima, juntamente com o crack apresentado na forma de "pedra" ou pó, a cinza torna-se esbranquiçada e, após o sorvimento da tragada pelo usuário, sua cor é sinal de destreza na prática de fumar: aqueles capazes de fumar com habilidade deverão ser também competentes em deixar a cinza o mais branca possível sobre o papel de alumínio, por vezes levemente côncavo, a fazer papel de fornilho, para não passarem por "frangos", ou seja, neófitos inábeis. A cinza branca indica queima total da "pedra" lá colocada. Indica destreza e ausência de desperdício. O "frango" em uma roda de crack pode ver-se na situação de ser, além de alvo de chacota, o mais solicitado a "fortalecer" ${ }^{8}$ outros participantes da roda. Segundo interlocutores, pode, em casos extremos, ou em rodas com desconhecidos e/ou em "biqueiras" ${ }^{9}$ afastadas de sua "área", ${ }^{10}$ ser roubado e até vítima de sequestro relâmpago, caso aparente ter conta em banco e possuir cartão de saque. Assim sendo, no ritual de uso do crack, a aparência da cinza após a queima da "pedra" possui agência como signo mediador do prestígio do usuário na roda.

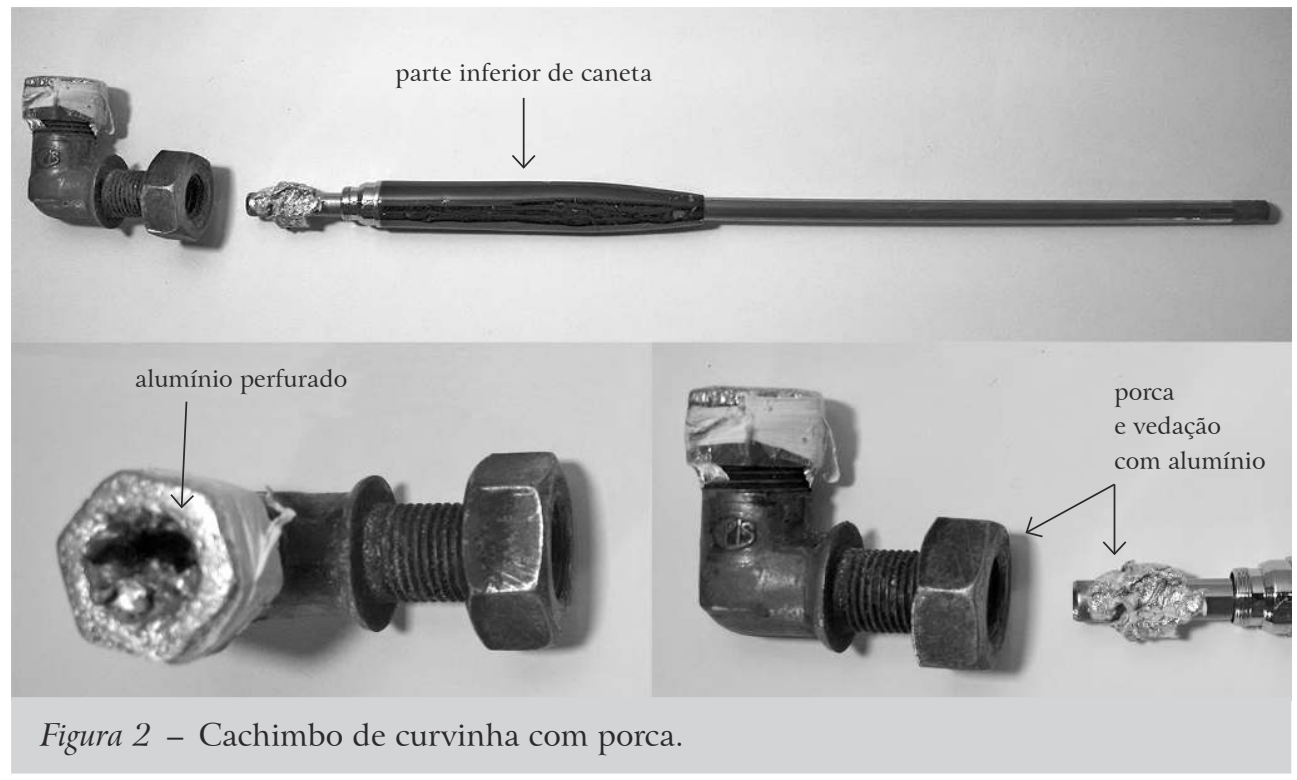

Este cachimbo pode ser considerado o estado da arte em termos de "Boris". Destacam-se o "caninho" e o fornilho/"fogãozinho" do tipo "curvinha", muito valorizado entre os usuários devido ao cobre utilizado em sua fabricação capaz de produzir uma "rapa" branca e não preta, considerada de menor qualidade

8 "Fortalecer" designa neste contexto o ato de fornecer crack a alguém como um grande favor.

9 "Biqueira": local de comércio e por vezes de consumo de crack.

10 "Área": local de moradia ou de consumo regular de crack onde se é conhecido. 
em comparação à primeira. ${ }^{11}$ Possui porca rosqueada ao fornilho e também a uma caneta por onde passa o "caninho". Juntamente com um papel de alumínio colocado entre o "caninho" e a parte interna do fornilho, promove ampla vedação do sistema e um "trago" muito agradável. "Caninhos" mais longos permitem o consumo de uma fumaça mais fria e o termo usado para esta prática é "buscar longe". Após uma tragada, diferentemente do cachimbo para tabaco, no "Boris" o fornilho não serve para colocar fumo, cinza, ou "pedra", mas como câmara de gás, e lá a desejada fumaça oriunda da queima da "pedra" sobre a cinza se concentra após o "trago". O objetivo do "chimbó", outro nome para o cachimbo, é permitir a rápida e total queima da "pedra" para produção da fumaça a ser absorvida após cumprir seu trajeto iniciado no fornilho, se estendendo pela haste até a boquilha, passando pela cavidade bucal, faringe, laringe, até atingir a traqueia e se dividir entre os brônquios direito e esquerdo para através destes chegar aos bronquíolos e à corrente sanguínea. Segundo alguns, a confecção destes artefatos, com sua grande riqueza de detalhes, é preferencialmente realizada sob a "brisa" (efeito) do crack - ela aumentaria, nas palavras de um ex-usuário, a sensibilidade artística do craqueiro/artesão.

No "trago", a fumaça é absorvida no pulmão e pode ser eliminada tanto pela boca, o mais comum, quanto pelo nariz. Enfim, deseja-se obter fumaça, é ela o bem valorizado no momento do "trago". Após este, a boquilha é comumente tampada para evitar-se a perda da fumaça que não pôde ser tragada apesar do esforço feito pelo diafragma e pulmões. O topo do "fogãozinho" também se encontra coberto pela cinza requeimada no processo de combustão da "pedra". A fumaça fica presa dentro do sistema que compõe o "chimbó" de fumar "pedra". É possível sorver com relativa tranquilidade a fumaça aspirada, pode-se respirá-la e, se o usuário quiser ou tiver necessidade, conversar, pedir algo, beber água ou alguma bebida alcoólica de sua preferência, enquanto a boquilha é obstruída firmemente com o polegar, até um derradeiro "trago", colocando o isqueiro aceso novamente sobre o topo do fornilho. Após esta repetição, a cinza poderá ser retirada e a boquilha liberada. Se não houver nenhum reparo a fazer no "Boris" e disponibilidade de "pedra", cinza e isqueiro, o processo poderá ser reiniciado quando for conveniente, minimizando-se o desperdício.

No "Boris" ou "chimbó", o material depositado no fornilho e no "caninho", a "rapa", corresponde à parcela daquilo que se intenciona consumir. ${ }^{12}$

11 Ao entrar em contato com um usuário de posse de cachimbo "feito de cobre" em sua pesquisa de campo, Rui (2012) ouviu uma explicação de um redutor de danos sobre as vantagens do cobre: "Os redutores disseram-lhe que o cobre é um dos melhores materiais para a confecção do cachimbo: não provoca intoxicação como o alumínio; aguenta o calor, diferentemente do plástico; não quebra como o vidro; mas tem a desvantagem de ser mais caro". Porém, não parece ter obtido do usuário informações sobre as vantagens da "rapa" branca.

12 A sublimação da fumaça não ocorre em uma câmara separada, como no caso do cachimbo de tabaco, ou seja, entre o pescoço do fornilho e o encaixe da haste, dando-se por toda a extensão [continua] 
Não esqueçamos que a superfície do "fogãozinho" não tem contato direto com a "pedra" e tampouco com a cinza queimada sobre o alumínio no topo da câmara. Assim sendo, o "fogãozinho" é integralmente raspado para a retirada da borra depositada. Esta é novamente fumada. Pode ser constantemente misturada à cinza que vai se obtendo na queima de cigarros em um processo de esmagamento da borra colocada em meio à cinza sobre uma superfície de apoio. Um cartão de visita ou carta de baralho geralmente presta-se a essa tarefa, sendo com ela misturada a borra retirada da haste e "fogãozinho", geralmente após o desmonte do conjunto. Tudo é amassado, novamente espalhado e amassado outra vez até que atinja a aparência desejada. Com o cartão levemente arqueado no sentido do lado mais longo, a mistura é colocada com o apoio dos dedos indicador e polegar, para evitar desperdício de material, sobre o fornilho do "chimbó", estando, assim, apta a ser fumada ou entregue a outro integrante da roda de crack.

O desmonte do "chimbó" é feito para a retirada da "rapa" ou para algum reparo, como trocar o isolamento de plástico que possa estar permitindo o escape de fumaça do "fogãozinho". Esta retirada requer a soltura do plástico derretido, geralmente grudado à parede externa do "fogãozinho" que veda o cachimbo ao prender o "alumínio" dobrado sobre suas laterais. Após a retirada da parte derretida, todo o plástico vedante pode ser removido, assim como o alumínio. Este pode ser reparado e/ou raspado para retirada da "rapa" ali grudada, que tende a fechar os furos do alumínio indispensáveis à entrada da fumaça oriunda da queima da "pedra", sobre ou misturada com cinza de cigarro. A retirada dessa borra requer um cuidado maior para não danificar o metal, principalmente no caso de um alumínio que se queira reaproveitar. Pode-se usar papel ou o mesmo plástico de vedação para a limpeza.

Para a retirada da borra do "fogãozinho" e "caninho" usa-se material contundente, de espessura suficientemente fina para permitir-lhe alcançar e percorrer todo o interior do "fogãozinho", "caninho" e encaixe quando houver. $\mathrm{O}$ "raspador" pode ser um pedaço de arame qualquer ou uma vareta de guarda-chuva, esta última muito valorizada por ser longa e possuir um formato côncavo apropriado à raspagem sem retirar material metálico das paredes do "fogãozinho". Este material, caso retirado, se uniria à "rapa", podendo influenciar seu gosto, assim como provocar males à saúde, ou seja, esse é um procedimento espontâneo de redução de danos por parte dos usuários de crack.

Soma-se à parafernália de uso um pedaço fino de arame qualquer, ou mesmo o alfinete de um brinco que se preste à finalidade de produzir os furos

do "Boris". Isto faz o material se depositar por toda a haste, além do "bolo" depositado no fornilho. No caso dos cachimbos de madeira utilizados no consumo de tabaco, este bolo deve ser mantido até a espessura de 1,5 mm. Caso cresça demais, reduzirá a capacidade do fornilho. Porém, quando retirado, não deverá sê-lo em sua totalidade, já que a presença do bolo é fundamental no uso de cachimbos com fornilhos de madeira. 
necessários no "alumínio" do cachimbo, o "furador". Sobre estes furos vai a cinza de cigarro, inclusive ao fumar-se na embalagem de Yakult ou no copo de água descartável. O cigarro é fundamental para o consumo do crack. Isso é socialmente traduzido na figura do "cigarreiro", pessoa presente nos locais de consumo e responsável por abastecer os usuários com cigarros, vendidos em maços ou a granel, ou mesmo trocados por "tragos". Ele é comumente chamado por este nome e, assim, o usuário necessitado de seus serviços pode simplesmente gritar "cigarreiro!" e logo este se aproximará com o maço à mão. ${ }^{13}$

\section{O "BLOCO” E O "TRAGO"}

Quando produzido no Brasil, o "bloco" ou "pedra" de crack é geralmente feito a partir do cozimento da pasta base da cocaína, ou "giz", com bicarbonato de sódio. Isto pode ser feito, por exemplo, em uma panela de pressão sobre a chama de um fogão doméstico, ou em uma fogueira numa calçada ou praça pública. Para aumentar a lucratividade, impurezas podem ser acrescidas, como farinha ou Maizena. Portanto, existem "pedras" com diferentes níveis de pureza e os usuários estão muito atentos a isto. Reclamam da má qualidade da "pedra" de uma "biqueira", deixam de adquirir em um local e o trocam por outro, exaltam a "pedra" da Cracolândia em detrimento do "bloco" do bairro e vice-versa, podem comentar haver no bairro o melhor "bloco" e no centro o pior. Assim, sua qualidade pode variar com o fornecedor, havendo "blocos" considerados do tipo A, B ou C. Ou mesmo, com nomes próprios como a "Incrível Hulk", merecedora deste apelido devido a sua cor esverdeada e alta qualidade. Há também a "pedra a óleo", feita exclusivamente da parte superior da fervura da pasta base com o bicarbonato e água, sem o acréscimo de impurezas. Importante frisar que é um erro considerar o crack uma espécie de subproduto da cocaína, tanto quanto a feijoada foi, segundo observou Bolaffi (2004), há tempos, considerada "a sobra" do alimento da Casa-Grande. A grande quantidade consumida em ambos os casos não permite a produção por "restos". Fica aí, mais provavelmente, uma questão de classe reforçada ideologicamente a partir de certos produtos. Por esta forma de pensar, o crack do pobre e a feijoada do escravo só poderiam ser feitos a partir das sobras do leitão do Senhor e da cocaína dos ricos. Mas não são! Enfatizamos que o crack é produzido da mesma pasta base da produção da cocaína, fato confirmado por relatos de quem produziu as duas variedades e pela literatura, como presente em Araujo (2012).

O tamanho da "pedra" é padronizado em uma cidade, ou região. Em São Paulo, ao adquirir-se uma "pedra", espera-se obter o suficiente para seis

13 A presença do "cigarreiro" diz respeito à Cracolândia ou lugares com um número considerável de usuários. 
"tragos"; na cidade de Santos, o dobro. O "trago" é a unidade de consumo do "bloco". Pode significar tanto a quantidade colocada sobre o cachimbo, ou "Boris", quanto o ato de fumar. Alguém, ao "favorecer" ${ }^{14}$ outro, pode referir-se ao pedaço do "bloco" ofertado como "trago", "está aí seu trago", e quem recebeu o pedaço da "pedra", ao fumar, pode observar: "agora, vou dar meu trago". Salientamos que "dar um bom trago" pode ser considerado o objetivo final do usuário e da roda de crack; para tanto há de contribuir uma série de fatores. Mesmo esta unidade, o "trago", pode ser repartida. O ato de colocar a boca no orifício do "caninho" do cachimbo e aspirar a fumaça, enquanto com o Bic aceso queima-se a "pedra", pode ser dividido geralmente em dois movimentos. No primeiro, comumente aquece-se previamente o "trago" colocado sobre a cinza do "Boris", antes de iniciar sua aspiração. Com isto, o "trago" derrete e mistura-se à cinza, formando um todo mais coeso e estável em comparação com o pedaço do "bloco" solto sobre o "alumínio" perfurado do cachimbo. Isto permite a movimentação do conjunto para os lados e facilita o contato com a chama evitando a queima dos dedos, particularmente o polegar, caso seja necessário inclinar-se o isqueiro $90^{\circ}$ para acender um cachimbo com o "fogãozinho" postado na vertical. Assim, é possível compreender a existência de usuários habituais de crack que possuem os dedos preservados, sem queimaduras. ${ }^{15}$ Certa vez, perguntei a um "vapor" ${ }^{16}$ porque alguns usuários de crack deixam os dedos queimados e outros não: "Esse negócio de queimar o dedo, também queima quem quer, né?" Resposta de Dobem: "Não, quem deixa se levar. Sou da marginália, sou do crack". Deixar os dedos queimarem e portar no corpo as marcas estigmatizantes de usuário de crack pode estar vinculado ao desejo de, através da marca corporal, demonstrar certa adesão a um grupo estigmatizado e a um modo de viver.

Após aspirar a primeira vez, pode sobrar parte do "trago" não consumido sobre a cinza. Este será fumado em nova combustão sob a chama do Bic e aspirado. Assim, o "trago" estará completo. Ao mesmo tempo, entre um movimento e outro, parte da fumaça pode ser preservada após o "trago", no interior do cachimbo, bloqueando-se o "caninho" com o polegar. Tanto esta fumaça restante no interior do cachimbo quanto o resto de "trago" não queimado podem ser dados em "favorecimento" a alguém, ou "segundinha". Entra, então, no circuito da "treta, ${ }^{17}$ de que falaremos a seguir.

14 "Favorecer" no contexto desta frase é o ato de fornecer crack a alguém, porém com um comprometimento em termos de gravidade da situação e dívida adquirida menor que "fortalecer" alguém.

15 "O constante aquecimento dos cachimbos fere ainda os dedos utilizados para bem posicionar o instrumento durante a tragada" (Rui 2012: 271). Parece-nos que, ao invés deste registro, a queima dos dedos deve ser buscada em uma dinâmica relacional mais complexa que a simples mecânica de uso.

16 "Vapor": pequeno traficante, por vezes também usuário.

17 "Treta": troca generalizada de "pedras" de crack e outros bens. Por vezes, serviços também podem entrar no circuito da "treta". 


\section{A RODA DE CRACK}

Pessoas sentadas próximas umas das outras, fumando e interagindo entre si, sob os efeitos excitantes da fumaça inalada, constitui uma prática possivelmente anterior ao surgimento das primeiras civilizações humanas e que ainda está presente entre usuários de crack. O cachimbo não passa obrigatoriamente de mão em mão, mas há compartilhamento ocasional. Geralmente, cada usuário dispõe de cachimbo próprio e este é constantemente aferido, arrumado, consertado, rearranjado e mesmo refeito. Como um "bloco" pode ser dividido em seis "tragos" em média e como o objetivo da roda é, e isto é importante salientar, proporcionar a todos um bom "trago", ${ }^{18}$ dificilmente ele será fumado na integralidade por um único usuário. Este será possivelmente convidado a "favorecer" ou mesmo "fortalecer" alguém. O primeiro termo, como já afirmado, tem um significado mais brando em relação ao segundo e é mais trivial. ${ }^{19}$

A circulação dos "tragos", ou sexta parte do "bloco", assim como do material necessário para o reparo dos cachimbos e consumo do "trago", como cigarro, "furador" e Bic, fazem parte da "treta". Nela, além do já exposto, entra tudo aquilo passível de ser trocado: vestimenta, calçado, telefones celulares, relógios, água e comida (embora a venda ou mesmo a simples troca destes dois últimos itens seja algo muitas vezes mal visto) e, é claro, dinheiro. Um "trago" pode ser comprado por dois reais, ou trocado por uma camisa na roda de crack, antigos favorecimentos podem ser lembrados e retribuídos. Vínculos de amizade, relacionamentos amorosos e hierarquias são postos à prova e então confirmados, fortalecidos ou fragilizados e até mesmo destruídos. A "treta" é um agenciamento constantemente presente na rede social dos usuários; nela, diversas materialidades são colocadas em relação e traçam a tessitura das interações.

O ethos subjacente a estas práticas tem na "sintonia" seu sentimento positivo norteador e na "radiação", o negativo. A "sintonia” é o sentimento de confiança e empatia entre usuários partilhando a mesma droga, o contexto favorável à "brisa" deleitosa, uma agradável sensação de paz, segurança e comunhão. A "radiação" é seu inverso. É a discórdia, a desconfiança, o medo. É o efeito de alguma pessoa "meter o louco" ou "arrastar" outra ou mesmo todo um grupo. É a quebra da reciprocidade, o roubo, a traição, o abuso de confiança e o desrespeito. Uma "brisa horrenda, medonha" também tem o poder de trazer

18 "Dar uma paulada" também é uma expressão utilizada.

19 "Fortalecer" alguém seria como fazer-lhe um imenso favor, enquanto ser favorecido significa ser ajudado, ou receber algo de valor, porém, sem que resulte em uma grande dívida ou obrigação. Ao pedir para ser fortalecido por um "vapor" em uma "biqueira”, um usuário disse: "pode chamar nós até pra carregar caixa eletrônico e pode pá” - dispõe-se a trabalho perigoso em troca de um grande favor e faz do "vapor" seu credor. 
"radiação". Pode "arrastar", contaminar todo um grupo e mesmo gerar "aproximação”, expor aquelas pessoas, chamar a atenção sobre elas. Neste sentido, a "brisa" é também performance (Almeida e Eugenio 2008) e parte constituinte do contexto de uso, como no diálogo abaixo obtido no campo:

"Ygor - Cara, vem cá, brisa é uma coisa mal vista, né?

Antônio - Aí depende. A brisa, o efeito que ela dá. Tem brisa que você fica, poxa, você acaba roubando a brisa do outro. O que é de prazer, o que é de curtir. Porque você vai ficar preocupado com alguém que vai ficar olhando pra você. Assim, não fica sossegado. Então, o cara que tá curtindo numa boa, acaba tendo a atenção virada pra você.

Ygor - O cara que tá curtindo numa boa, tá brisando também.

Antônio - Claro. A sua brisa é diferente. Acaba sendo medonha, horrenda. Arrasta. 'O cara arrasta, meu. Você é louco'. Arrasta, ou seja, muito mal visto. Chama muita gente pra ficar olhando. Fica chamando radiação pra cá. Aproximação. 'Não dá pra fumar com esse cara não. Vamos embora'. Tem cara que entra dentro dos hotéis e fica de boa lá, assistindo televisão a noite inteira, trocando ideia. Não fica encanado com ninguém. 'Eu tô pagando essa porra. Tô pagando, tô usando a minha droga, não roubei de ninguém. Vou ficar aqui de boa, cara. [Risos] Que se foda todo mundo'”.

Vimos como se dá um "trago", agora devemos salientar seu aspecto coletivo. O proibicionismo e a ilicitude formam o pano de fundo, o dado estrutural fundamental do consumo de crack. Lidar com isso, ser capaz de usar sem medo é condição para a "sintonia" e, objetivamente, para a segurança do grupo desviante. A roda de crack não se encontra alheia ao mundo. É parte de seus valores o respeito pelos não usuários. "Olha o anjo" é uma frase pronunciada, por exemplo, na aproximação de uma criança e imediatamente o uso cessa em sinal de respeito. O mesmo ocorre na passagem de qualquer não usuário por perto, por exemplo um transeunte. Os usuários são conscientes do impacto negativo causado pela sua prática e o evitam, tanto quanto ou até mais do que se guardam de serem vistos pela polícia. Não se encontram, portanto, fora de nossa cultura, mas fazendo dela uma leitura alternativa. Existem, assim, situações em que agirão dentro do considerado majoritariamente como "normal", enquanto, em outras, podem adotar comportamentos divergentes (Velho 2013: 50). Certamente, existem situações em que pode ocorrer o uso individual, como quando, no decorrer de uma "caminhada", o usuário se encontra longe de seu local de permanência mais constante, ou então quando ele esteja de posse de uma quantidade demasiadamente pequena da substância. Porém, o uso em roda, na companhia de "parças" é o preferencial. Tanto dentro quanto fora da roda, a "treta" é generalizada. Além disso, insumos vindos de fora são frequentemente necessários e bem-vindos. Um usuário em uma roda 
pode chamar a atenção dos vizinhos para suas necessidades e possibilidades de troca. "Quem favorece água? Favoreço cigarro! - Cigarreiro!"

\section{A "BRISA"}

Para um neófito, aprendiz do uso do crack, o indicador de que está "brisando" pode ser um zumbido no ouvido. É muito comum ouvir a máxima "cada um tem sua brisa”. Assim, esse aspecto idiossincrático da percepção dos efeitos (MacRae e Simões 2000: 15) deverá ser considerado em seu contexto social abrangente. A "brisa" certamente varia, mas esta variação, seja ela qual for, se dá em um contexto de uso. Um usuário, com formação acadêmica e de classe social superior à do comum dos frequentadores de certa "biqueira", pode "brisar" corrigindo reiteradamente a gramática dos demais participantes da roda de crack. Uma senhora beirando os 70 anos, frequentadora de uma "biqueira" com "fumódromo", quando "brisava", se levantava e permanecia soturna e estática, com a bolsa sob o braço, como se fora partir. Tal sinal corpóreo, tomado como indicador de que o uso está tendo os efeitos desejados, é procurado pelo novo usuário a partir de indicações feitas pelos outros na roda de crack, durante o processo de aprendizado (Becker 2008 [1963]: 55) para identificar efeitos e atribuir a eles uma positividade. Isto é similar ao que ocorre entre usuários de maconha em uma roda de fumo (MacRae e Simões 2000: 16).

"A brisa boa é quando dá um tuim". Ao perguntar a Salomão, um usuário, como era sua "brisa", obtive a seguinte resposta: "Depende do lugar e da circunstância". A "brisa", tida como sensação agradável, depende da "sintonia" na roda de crack. Outro usuário, Zezé, cercado por revistas pornográficas em seu barraco e na presença de uma moça jovem e bonita, diz: "Eu uso porque me dá prazer. Se todo mundo tivesse a brisa que eu tenho, o crack não ia valer dez, ia valer trinta [...] Porque minha vida é boa, entusiasmado pra trabalhar, planejo e executo. E tenho um grande aumento da libido [...] A minha brisa é a libido". O mesmo usuário, alijado do contexto de seu barraco, sentirá outro efeito, não será mais o prazeroso descrito acima, mas o crack passará a servir como combustível para o corpo fatigado. Como sempre salientado por Zinberg (1984), mudado o contexto, altera-se o propósito, varia o efeito.

"Zezé - Eu sou uma pessoa ainda presa a situações sociais que me deixam com vergonha, inseguro de fumar numa calçada. Não tenho brisa. Se estiver fumando em uma calçada é pra ficar acordado, pra seguir em uma caminhada. Não pra poder ter prazer. Prazer pra mim é estar fumando dentro de um barraco. Lendo uma revista, trocando uma ideia, alisando uma gostosa. Mas, na rua, eu tô ali, no meu limite. Lembra da agulha vermelha do combustível já acabando? Eu estou na calçada, buscando uma treta pra me manter acordado até o próximo lance, um trabalho, o próximo [...]". 
O uso no "corre", como observa o usuário Zezé acima, não é hedonista, mas voltado à produtividade do trabalho, é combustível a ser queimado. Porém, este mesmo "corre" pode ser considerado como o conjunto de práticas baseadas na "treta" para obtenção dos fundos necessários à obtenção da droga. Num cotidiano absorvente, é capaz de proporcionar a aventura de um dia inteiro para quem, de outra forma, poderia estar entediado ou frustrado (Leary 1999 [1983]: 432). O chamado "binge" de crack, ou seu uso até esgotarem-se todas as forças e posterior estado de prostração do usuário, pode ser compreendido na situação de rua como associado a um estilo de vida. Como não há espaço físico para se dormir confortavelmente, o sono só viria como resultado e possibilitado pelo completo esgotamento de forças. Ao encontrarmos Zezé neste dia, ele havia acabado de acordar em seu barraco e estava bem-disposto; porém, juntou-se a nós um usuário que declarou estar acordado tinha cinco dias - ele não possuía barraco e possivelmente só viria dormir no completo esgotamento de suas forças.

O uso do crack pode estar ligado a "brisas" as mais distintas possíveis, como a de Vó, descrita anteriormente e que consistia em levantar-se e agarrar a bolsa, permanecer silenciosa, estática e aparentemente pensativa. O "corre" como é vivenciado pelos usuários pode corresponder àquilo que $\mathrm{T}$. Leary descrevia como uma aventura capaz de preencher um dia inteiro, porém é interessante observar como a "brisa" pode preencher o cotidiano e transformar-se em estilo de vida, como no caso de Esmeralda, o de menina ladra de rua.

"Eu não gostava de traficar, porque a minha noia era roubar, onde eu estivesse. Podia ter até mil reais na mão, ter droga dentro da calcinha, que eu dava um pega e tinha que roubar. Não sei por quê, eu tinha que roubar. Cada um tem um tipo de obsessão, a minha era roubar. [...] Uma coisa muito boa também é ser honesta. Isso é legal, porque de vez em quando vem a vontade de roubar. Às vezes do nada vem a vontade. Às vezes eu seguro minha mão e ando assim no meio da rua. É mais no centro da cidade que me dá vontade. Então eu ando segurando minha mão, porque é compulsivo, roubar vira uma doença" (Ortiz 2001: 104, 207).

Essa era uma "brisa" de roubar em uma vida na rua como ladra. O efeito do uso do crack em determinado meio permite a exteriorização da interioridade da "brisa" como disposição durável, se tornando um princípio gerador de práticas regulares associadas a este meio - no caso de Esmeralda, o ato de roubar no centro da cidade de São Paulo. Assim, o uso do crack por uma menina em situação de rua como Esmeralda pode predispor a um estado habitual de seu corpo, ao ponto de ela ter de segurar a mão, ser uma tendência, inclinação ou propensão, enfim, como exposto por Bourdieu (2003), parte de um habitus como sistema de disposições. Entender a "brisa" como uma disposição que em determinada exterioridade pode compor um habitus nos abre a possibilidade 
de novo olhar sobre a expressão "sou da marginália, sou do crack" e a corporalidade do craqueiro, com seu andar peculiar, meio arrastando as pernas um pouco bambas, sua voz por vezes extremamente rouca, seus dedos queimados, a boca rachada e por vezes com um pouco de baba branca a se acumular nas laterais dos lábios. Acompanham estas características físicas suas roupas geralmente sobrepostas em arranjos criativos de camisetas por cima de camisas e bermudas a cobrir calças. Assim, ser do crack é possuir certas percepções sobre os acontecimentos na rua, como a "radiação", ser capaz de certas apreciações, julgamentos e ações. Ser do crack é ter discernimento quanto aos riscos e possibilidades da vida em torno de uma "biqueira", enfim, dispor de uma "matriz de percepções, de apreciações e de ações" (Bourdieu 2003: 57, itálico no original) que torne possível a realização, entre outras ações, da "treta" e do "corre".

Outro usuário nos afirmou que fumar na rua, exposto à presença da polícia e de não usuários, lhe "rouba a brisa". William Burroughs (2013 [1953]: 73) fala em "tiranoia", a paranoia capaz de assemelhar todos a tiras. Portanto, para dar-se um "trago" e obter a "brisa" desejada não é suficiente o importante serviço prestado pelo "vapor" aos usuários, ao proporcionar o "bloco" em local com condições propícias à "brisa". É possível que este "trago" seja considerado um desprazer, ou seja, "dar um trago" sem obter os efeitos desejados. Um local pouco apropriado pode tornar a "brisa" difícil ou mesmo impossível. Até uma companhia desagradável coloca em risco o "trago". Um "Boris" mal calibrado, com furos a mais ou a menos no "alumínio", pode tornar a tragada inviável a quem esteja sem fôlego devido a um longo período de uso ininterrupto, por exemplo. Um plástico mal colocado pode queimar e, assim, contaminar a fumaça inalada e estragar o seu sabor. Um "caninho" entupido pela "rapa", com comprimento ou largura inadaptada ao conjunto "fogãozinho"/“alumínio", ou uma entrada de ar por fora dos furos do "alumínio", assim como tantas outras combinações destes fatores fazem do cachimbo de se fumar crack algo de grande plasticidade e de difícil calibragem. Seus usos e os efeitos provocados são relativos aos diversos estados corporais do usuário, assim como ao seu estado de alimentação e descanso no momento da tragada. É corpo, contexto social e propósito de uso entrando em relação com uma droga e os meios de administrá-la e, todos em conjunto, ajudando a plasmar os efeitos percebidos (Fernandez 2007: 144).

\section{UM CONTEXTO PARA RODAS DE CRACK: O "FUMÓDROMO"}

O uso do crack depende do "fluxo". ${ }^{20}$ Ele garante a disponibilidade da droga e mantê-lo é obrigação do "vapor" para com os usuários e a "biqueira". Estar no "fluxo" é estar "na responsa", no dever de alimentar a "biqueira" com os 
“blocos". Não é à toa que o "vapor" está também no "corre". Às vezes ele está literalmente correndo, como pudemos observar entre a "biqueira" da "Estudantes" e o "fumódromo" a céu aberto da Rua São Paulo. Existem "biqueiras" stricto sensu, locais de mercado e não de consumo (Fernandes e Pinto 2004: 149) como a "Estudantes". Penso na etimologia do termo "biqueira" como relacionado às filas formadas em frente às fontes de água em favelas, a bica d'água. ${ }^{21}$

Ser "vapor" não é desempenhar o mesmo papel em qualquer lugar ou situação, independente do contexto. Ele pode ser mais ou menos ligado à "biqueira" ou estar mais ou menos por conta própria, a céu aberto ou em lugar fechado. Pode acumular funções de gestão do local de comércio e uso, além de se responsabilizar pelo transporte dos "blocos", agora agrupados no "pacote". Como uma espécie de concessionário, pode explorar e administrar um espaço de comércio ligado a determinada "biqueira". Tem a obrigação de manter o "fluxo" e o monopólio do lucro na venda do "pacote". Este lucro pode se dar na proporção de 14 para 10, medida observada em mais de um caso e confirmada por diferentes interlocutores. Cada "pacote" transportado ou recebido possui comumente a quantidade não acidental de 14 "blocos". Isso é fruto do cálculo entre o risco da posse material do "flagrante" e sua otimização logística. Carregar mais "blocos" significaria correr maior risco de ser preso como traficante; por outro lado, ir e retornar da "biqueira" com uma quantidade menor obrigaria a um maior número de viagens. Um "pacote" comercializado por unidades de "blocos", a 10 reais cada, possibilitaria o lucro de quarenta por cento, dado o valor a ser retornado à "biqueira". Isto pelo fato de o "pacote" custar 100 reais e a soma obtida pela venda de 14 "pedras" ser de 140 reais. O "vapor" teria por lucro esta diferença entre os 140 reais da venda e os 100 reais a retornar para a "biqueira". Porém, a rotina e as motivações de um "vapor" não se restringem a um cálculo tão simplório.

Os "blocos" em um "pacote" costumam sair da "biqueira" embalados um a um; porém, sempre há a possibilidade de o "vapor" ser responsável por estabelecer, ele próprio, as unidades para comércio. Seu produto são os "blocos" fornecidos por terceiros, sua praça a "biqueira" e o preço, em São Paulo, atualmente é fixado em 10 reais por "bloco". Resta então ao "vapor" explorar suas possibilidades de promoção. ${ }^{22}$ Tendo essa liberdade, ele a explora todo o

21 Ao serem ocupadas pelo tráfico, as favelas passam a receber uma clientela de não moradores, interessada unicamente em adquirir a droga ilegal. A ilegalidade impede o comércio livre da droga e a exila a espaços igualmente ilegais, distantes dos ditames da lei. Quando conseguem se suprir de água encanada através de ligações clandestinas, os chamados "gatos", seus moradores deixam de ter de se postar em fila na bica. Esta situação fica reservada aos frequentadores não residentes que vão em busca da droga, para eles tão preciosa à mente e ao corpo, como água para a vida. A sede se fez fissura, a água se faz "pó" e "pedra". Ao invés das latas de água na cabeça, bolsos e mãos fechadas a "segurar o flagrante".

22 Os quatro PP de Kotler e Keller (2006): praça, preço, produto e promoção. 
tempo. Nesse caso, trata-se de alguém que detém certa liberdade de ação e não de outro tipo de "vapor" que fica simplesmente postado em uma "biqueira", realizando o trabalho repetitivo de perguntar a quantidade, receber o dinheiro e entregar o "bloco". Um espaço de comércio e uso, muitas vezes, é abastecido por um(a) "vapor"/usuário(a). Do seu quinhão de lucro, de quatro "pedras" por "pacote", ele ou ela pode fumar uma, usar outra como moeda de troca pelos mais diversos bens e serviços, além de vender as outras na forma de promoção, por exemplo, seis "pedras" por 50 reais. ${ }^{23}$

O "vapor" desenvolverá habilidades de venda de acordo com as contingências de sua atividade. Anunciará sua chegada ao "fumódromo" em alto e bom som - "ó o blocão" - assim como alertará sobre "as últimas do pacote", na esperança de alguém adquirir logo suas derradeiras "pedras" ante a iminência de ter de aguardar novo carregamento. Atualmente, as "pedras" de melhor reputação são a "Incrível Hulk" e "a óleo". A tonalidade esverdeada da primeira a protege contra falsificações, mas o mesmo não ocorre com a última - assim, qualquer "vapor" da região central da cidade poderá declarar estar comercializando "pedras a óleo". Este fato é semelhante ao ocorrido nos anos de 1987 e 1988 na região sudeste do país. Aquino (2012) observa que com o despejo de 22 toneladas de maconha de excelente qualidade nas águas marinhas pelo barco de bandeira panamenha Solana Star, a droga acondicionada em latas fez imenso sucesso e, por alguns meses, todos aqueles dispostos a vender maconha declaravam estar comercializando canábis "da lata". O "vapor" precisa ter habilidades de negociação e ser o mais condescendente possível com seus clientes. Estes avaliam o papelote oferecido para compra e o apertam para senti-lo. Mesmo após aberto, o usuário pode decidir pela troca, caso não considere o tamanho da "pedra" condizente com suas expectativas. Quanto mais bem informado sobre a capacidade de compra dos frequentadores da "biqueira", melhor poderá o "vapor" promover a formação de consórcios entre os usuários e, assim, unir o possuidor de seis reais, por exemplo, com outro de quatro, possibilitando a ambos adquirir um "bloco" de dez reais. Porém, quanto mais o "vapor" puder fugir da responsabilidade da partilha do "bloco", deixando-a para os usuários, melhor ele se sente.

O usuário de crack comumente reclama: assim, ele pode "radiar", ${ }^{24}$ falando, por exemplo, que "essa aqui tá ruim". Isto ele faz na expectativa de, em futuras compras, ter a quantidade aumentada; além disso, uma "pedra" de tamanho mais avolumado pode gerar expectativas e frustrações quanto às demais. Não

23 Devemos considerar o "fluxo" como interesse da "biqueira" e valor em si mesmo. Retornar à fonte para novo carregamento significa trabalho bem feito pelo "vapor" na comercialização dos "blocos"; maior chance de permanência na função e a possibilidade de barganhas por "pacotes" mais "bem servidos" e "blocos" extras. Um "vapor" incapaz de garantir e promover o "fluxo" poderá ser substituído, terá de encontrar outra forma de fazer seu "corre" e bancar seu consumo de crack.

24 "Radiar", como referido acima, é uma expressão com o significado de trazer discórdia e incomodar. 
faltam artifícios ao "vapor". ${ }^{25}$ Ele pode oferecer múltiplas variações de preço e quantidade ao interessado, ou então deixar os últimos "blocos" em consignação, enquanto busca o próximo "pacote". Isto possibilita a manutenção do "fluxo" mesmo em sua ausência, pois está certo de que, caso apareça algum comprador potencial, a informação sobre a presença de algumas "pedras" nas mãos de determinado usuário e disponíveis para venda será imediatamente comunicada por algum "parasita", de quem trataremos mais à frente, ou pelo "contenção".

A "contenção" é uma atividade recorrente em "biqueiras" e "fumódromos". Consiste em receber os usuários, manter o mínimo de disciplina e alguma segurança com relação a investidas da parte de policiais, assim como de outros possíveis invasores. Varia conforme o contexto. Em uma "biqueira" localizada em comunidade favelada, por exemplo, o "contenção" pode ostentar uma arma e ser responsável por verificar as condições dos clientes, obrigando-os a levantar a camisa e a barra das calças, para se certificar que estão desarmados. Assim, no espaço da "biqueira", seria ele o detentor do monopólio do uso legítimo da violência. Ele tenta impor o mínimo de disciplina na fila de usuários enquanto esperam o atendimento. Neste interim, costumam reclamar do andamento do serviço, do fura fila, da qualidade da "pedra", ou comentam acontecimentos do dia relacionados à presença de polícia neste ou naquele local e discutem o estado de outras "biqueiras". Curiosamente, seu comportamento não é muito diferenciado do esperado para uma fila de banco ou mesmo para pegar água na bica. O "contenção" deve também garantir o atendimento preferencial e imediato às mulheres que são colocadas em fila separada da masculina. ${ }^{26}$ Cabe também a ele fazer certo esforço, embora geralmente sem muito sucesso, para impor o mínimo de seriedade correspondente a uma prática ilícita.

Em "biqueiras" menos estruturadas, o papel de "contenção" pode ser exercido por um "parasita" ali presente. Ao redor do "vapor" podem agrupar-se certo número de usuários dispostos a prestar serviços em troca de um "trago". Quando a gestão do "fumódromo" é deixada, totalmente ou em parte, sob a responsabilidade do "vapor", este poderá valer-se dos "blocos" a mais auferidos em cada "pacote" para pagar pelos serviços necessários ao funcionamento do local. Fazer a "contenção" é um deles, assim como varrer o chão, retirar entulho, buscar água, trocar moedas por notas, arrumar o barraco do "vapor",

25 O pagamento não precisa ser integral - “Troco pra galo [nota de 50 reais]", mas caso o vendedor esteja sem troco pode deixar os "blocos" com o comprador e recolher o dinheiro depois. Essa técnica de vendas possibilita converter a diferença a ser dada por troco em nova compra algum tempo depois, quando os "blocos" inicialmente adquiridos tenham sido consumidos. A negociação pode incluir ofertas por quantidades maiores, cinco "blocos" podem ser oferecidos a 40 reais, por exemplo, inteirando o troco que deveria ser inicialmente restituído.

26 Nas palavras de um usuário de crack: “[...] mulher não pega fila, às vezes tem fila, então, quando tem mulher, elas passam na frente dos caras, que é uma lei, então homem nunca pega primeiro [...]” (Oliveira 2007: 93). 
entre outras atividades. Ao abandonar momentaneamente a "biqueira", o "vapor" pode deixar alguns "blocos" sob a responsabilidade do "contenção", até seu retorno. ${ }^{27}$

A contabilidade do "fluxo" leva em conta certas informações: quantas "pedras" foram deixadas com quem, em qual ocasião, sob quais condições de preço e prazo para venda, e tantos outros favores e serviços prestados. Ela é feita periodicamente no "resumo". Este encerra uma "situação" e é periódico. O "resumo" pode ser uma experiência desgastante e de certa tensão, dependendo da existência ou não de disparidades de avaliação entre o "contenção", o "vapor", alguma outra pessoa de referência no "fumódromo" e responsável pelo "fluxo" no momento, além de demais usuários ou "parasitas" que por qualquer motivo tenham retirado "blocos" para venda em uma espécie de consignação ou "na confiança". Um representante dos interesses da "biqueira", presente no "fumódromo" com a finalidade de fazer o "resumo", irá acertar

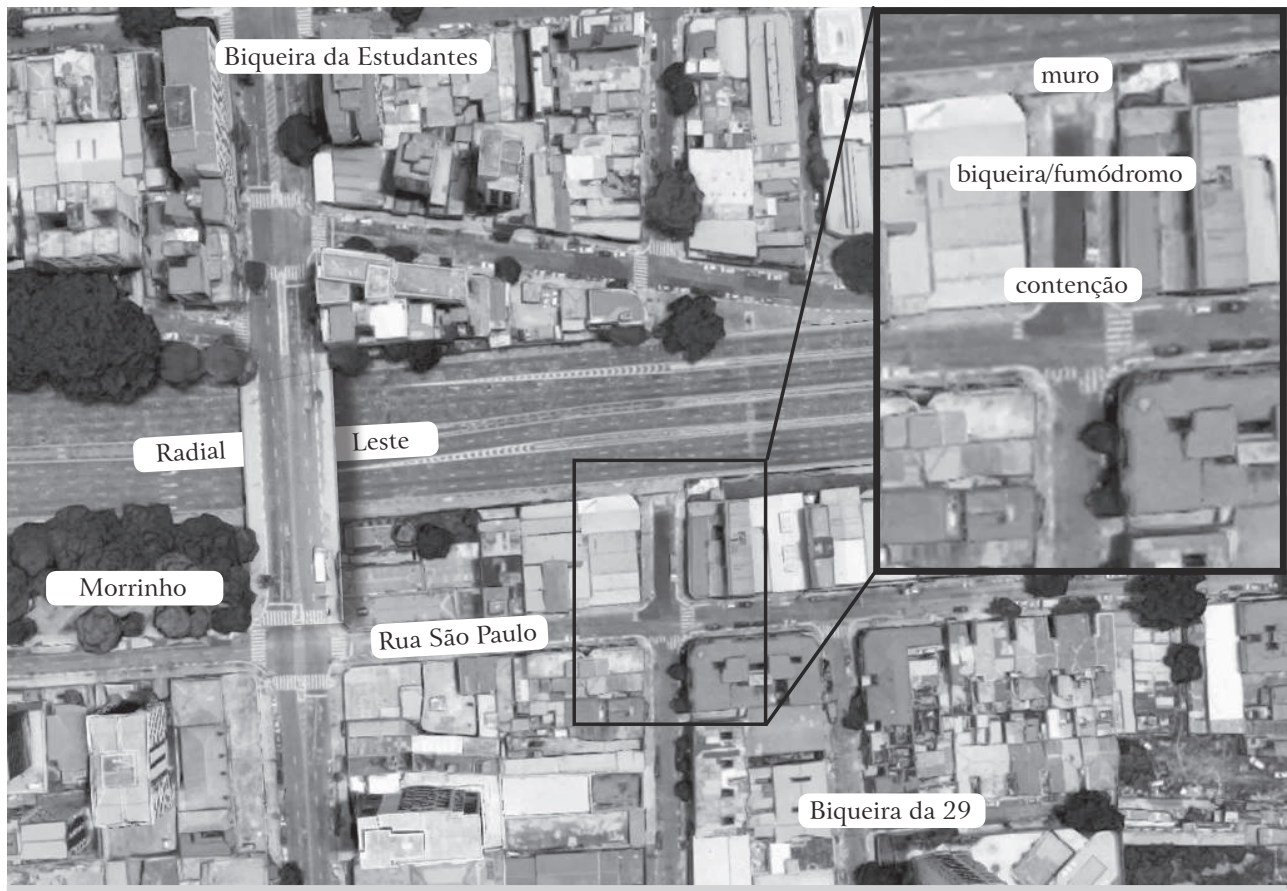

Figura 3 - Esquema do "fumódromo" a céu aberto.

27 Fazer a "contenção" em um "fumódromo" pouco estruturado é atividade menos importante em comparação à venda dos "blocos". A atividade pode ser desenvolvida por um indivíduo desarmado, ou em posse de uma faca para sua própria segurança. Um usuário antigo e frequentador do local não se sentirá intimidado pelo "contenção". Seu status não é muito superior ao deste usuário e mesmo o "vapor" só exerce maior ascendência sobre o grupo de "parasitas" a ele ligado e mesmo assim, de modo instável. 
com o(s) "vapor(es)", ou mesmo com um terceiro traficante de referência, espécie de coordenador dos "vapores", os valores alusivos a "pacotes" retirados e ainda não pagos. Os "vapores" acertam contas entre si, manejando inúmeras possibilidades de trocas, empréstimos e consignações de "blocos" deixados "na confiança" de alguém para finalmente o "resumo" poder ser feito com a "biqueira". A diferença de postura e vestimenta entre os "vapores" e os traficantes de referência é notória. Enquanto os primeiros parecem desejar deixar claro o quanto "são do crack", os últimos fazem o inverso.

Como mencionado acima, preservar os não usuários do impacto provocado pela visão do consumo de crack é um valor. Para tanto, recorre-se às tecnologias disponíveis na rua para o abrigo e intimidade. O "barraco" é a principal tecnologia disponível na rua para o abrigo e proteção; sua constituição é tão variada quanto são os materiais disponíveis, habilidade, propósitos e gostos pessoais. Pode ser construído a partir de materiais diversos como lona, papelão ou cobertores e ser apoiado em uma parede ou carroça. O barraco pode ter ou não um colchão, ser feito para se sentar ou deitar, ou mesmo para os dois propósitos. Surge, então, um ambiente íntimo, adequado para o uso seguro da droga, livre da vergonha de se estar agredindo os valores dos passantes, assim como da "radiação" vinda de fora. ${ }^{28} \mathrm{O}$ ambiente externo ao "barraco" está na verdade amplamente interligado a ele porque a "biqueira" com "fumódromo" a céu aberto, por exemplo, é um lugar extremamente agitado, onde a troca recíproca de todo o tipo de bens e serviços é constante. O "barraco" é suficientemente permeável a ponto de possibilitar a requisição de bens e serviços disponíveis no lado externo e, ao mesmo tempo, acompanhar alguma agitação maior na rua. Para a arquiteta Maria Cecilia Loschiavo (2005), o "barraco" está relacionado a:

"[...] culturas do desemprego, que levaram ao nomadismo, à bricolagem como formas de resistir à exclusão e criação de estratégias para sobreviver. Outro aspecto a ressaltar refere-se ao estabelecimento de uma justaposição da cidade formal com a cidade de plástico e de papelão, que frequentemente incorpora elementos do ambiente construído, como marquises, espaços residuais, baixios de viaduto, etc." (Loschiavo 2005: 14).

\section{CONCLUSÃO}

O uso do crack pode ser considerado como um constante refazer. O usuário de crack refaz seu cachimbo conforme as necessidades do corpo. Busca materiais, os troca na "treta" e os transforma em coisa, num renovado e vívido "dar 
forma". O cachimbo industrializado seria a morte da atividade frenética do artesão, agora engessada na forma acabada. O craqueiro não precisa de um plano de cachimbo preestabelecido na mente. Ele tenta, adapta, improvisa, molda, acomoda, compõe, inventa, põe em movimento, aviva e traz à tona os materiais (recicláveis) - presentes como forças no ambiente - no processo contínuo de geração do cachimbo como coisa sempre nova e diferenciada, pois adaptada ao corpo do usuário de crack, naquele momento particular. Os materiais presentes no "fluxo" são introduzidos em um fluxo de transformações. Neste sentido, o usuário está cercado de coisas a que ele mesmo ou seus pares deram vida em um campo de relações que os engloba: o cachimbo, o "barraco" com seu mobiliário e o carrinho para carregar material reciclado.

\section{BIBLIOGRAFIA}

ALMEIDA, Maria Isabel Mendes de, e Fernanda EUGENIO, 2008, "Paisagens existenciais e alquimias pragmáticas: uma reflexão comparativa do recurso às 'drogas' no contexto da contracultura e nas cenas eletrônicas contemporâneas”, em B.C. Labate et al. (orgs.), Drogas e Cultura: Novas Perspectivas. Salvador, Editora da Universidade Federal da Bahia, 383-408.

ALVES, Ygor Diego Delgado, 1998, Um Vício Deselegante: O Preconceito Racial e a Transformação da Maconha em Problema Público no Brasil. São Paulo, Pontifícia Universidade Católica de São Paulo, dissertação de mestrado.

AQUINO, Wilson, 2012, Verão da Lata: Um Verão que Ninguém Esqueceu. Rio de Janeiro, Texto Editores.

ARAujO, Tarso, 2012, Almanaque das Drogas. São Paulo, Leya.

BECKER, Howard S., 2008 [1963], Outsiders: Estudos de Sociologia do Desvio. Rio de Janeiro, Jorge Zahar Editor.

BOLAFFI, Gabriel, 2004, A Saga da Comida: Receitas e História. São Paulo, Record.

BOURDIEU, Pierre, 2003, "Esboço de uma teoria da prática”, em R. Ortiz (org.), A Sociologia de Pierre Bourdieu. São Paulo, Olho d'Água, 39-72.

BurroughS, William S., 2013 [1953], Junky. São Paulo, Companhia da Letras.

CASTRO, C.A., s.d., "Cachimbo", Confraria dos Amigos do Cachimbo, disponível em < http://www.amigosdocachimbo.com.br/artigos/art_cachimbo_fumar.htm > (última consulta em outubro de 2016).

FERNANDES, Luís, e Marta PINTO, 2004, "El espacio urbano como dispositivo de control social: territorios psicotrópicos y políticas de la ciudad”, em Uso de Drogas e Drogodependencias. Barcelona, Fundación Medicina y Humanidades Médicas, 147-162.

FERnANDEZ, Osvaldo, 2007, Coca Light? Usos do Corpo, Rituais de Consumo e Carreiras de "Cheiradores" de Cocaína em São Paulo. Salvador, Universidade Federal da Bahia, tese de doutorado. 
KOTLER, Philip, e Kevin Lane KELLER, 2006, Administração de Marketing. São Paulo, Pearson Prentice Hall.

LEARY, Timothy, 1999 [1983], Flashbacks “Surfando no Caos”: A História Pessoal e Cultural de Uma Era. Uma Autobiografia. São Paulo, Beca Produções Culturais.

LOSCHIAVO, Maria Cecilia, 2005, "Arquitetura, os moradores de rua e a transfiguração de nossa sociedade", Arqtexto, 7: 12-15.

MacRAE, Edward, e Júlio Assis SIMÕES, 2000, Rodas de Fumo: O Uso da Maconha entre Camadas Médias Urbanas. Salvador, CETAD/Editora da Universidade Federal da Bahia.

OliveirA, Lúcio Garcia de, 2007, Avaliação da Cultura do Uso de Crack após Uma Década da Introdução da Droga na Cidade de São Paulo. São Paulo, Universidade Federal de São Paulo, tese de doutorado.

ORTIZ, Esmeralda do Carmo, 2001, Por Que Não Dancei. São Paulo, Editora Senac.

RUI, Taniele Cristina, 2012, Corpos Abjetos: Etnografia em Cenários de Uso e Comércio de Crack. Campinas, Instituto de Filosofia e Ciências Humanas da Universidade Estadual de Campinas, tese de doutorado.

VELHO, Gilberto, 2013, "O estudo do comportamento desviante: a contribuição da antropologia social”, em G. Velho, Um Antropólogo na Cidade: Ensaios de Antropologia Urbana. Rio de Janeiro, Jorge Zahar Editor, 36-51.

ZINBERG, Norman E., 1984, Drug, Set, and Setting: The Basis for Controlled Intoxicant Use. New Haven, CN, Yale University Press. 